\title{
Providing a Suitable Model for Solving Resource Leveling in Project Management
}

\author{
Mahtab Afsari \\ PhD student, Institute of Product Development, Leibniz University Hannover, Germany \\ afsari@ipeg.uni-hannover.de \\ Hesam Javadi Vasigh
}

Msc Industrial Management, Tehran, Iran

\section{Doi:10.5901/mjss.2016.v7n2s2p116}

\section{Abstract}

Resource leveling and resource Allocation are main tasks of project management. The aim of project scheduling is allocating resources to activities while faced on minimizing some economic objectives. In particular, in resource leveling problems the objective is to minimize a function of the resource utilization over time. If there is no restriction on the amount of available resources, raised the issue of resource leveling is required to fluctuations in resource utilization decreases without increasing the project duration. In this paper for managing transportation resource leveling problem, especially when based on multiple objective function of NP-hard problems, has been used Genetic Algorithm. This method is inspired from nature, presented as well as the desired resolution and optimal solutions. The results indicated that the genetic algorithm is able to respond very well at a reasonable offer.

Keywords: Resource leveling, Project Management, Genetic algorithm

\section{Introduction}

Fuzzy logic in project control introduced on beginning of the 70's. [Lachmayer \& Afsari, 2012]. Technological change and globalization, many organizations have made in solving their problems using maximum optimization of the use of its scarce resources and this trend has increased the importance of research in the science of optimization [Rieck et al, 2012].

Resource leveling and resource Allocation are two main tasks of project management. Typically, in project management for plan and project control used specific methods such as PERT, GERT, CPM, and PN [Drótos et al, 2011]. In these methods, where the available resources are limited, the issue of resource allocation arises and it is necessary to such activities are planned in no case be higher than the level to be required. In such a situation, it may be necessary to time project be longer than the least amount of minimum time [Drótos et al, 2011, and Lachmayer \& Afsari, 2013 ].

In cases where there is no restriction on the amount of available resources, arises resource leveling. After calculating the critical path and considering the resource consumption curve, while volatility is significant use of resources in different periods should be minimized fluctuations resource leveling techniques [Kellerer et al, 2004]. This makes more efficient use of resources. It should be noted that the resource leveling project does not change completion date [Rieck et al, 2012].

The purpose of resource leveling is possible to close the resource consumption on different days to minimize fluctuations in resource utilization [Drótos et al, 2011].

The resource leveling can expressed an attempt to achieve a better distribution of the effective use of resources [Kolisch et al, 1999]. In this paper, the issue of resource leveling of the transport rate with regard to production volume supplier in the amount of orders per day to be supplied that increased differences in the use of vehicles in the planning horizon.

Technological change and globalization may have organizations make maximum use of its scarce resources their own problems using science to solve many optimizations (accurate and inaccurate models) and this trend has increased the importance of research in the optimization science [Hartmann et al, 2010]. Also, the inability to use of science to be irreversible impact on the competitive position of companies. 


\section{Literature Review}

Resource leveling has partly due to academic disciplines. Kolisch introduced a bunch of instances with 30 activities remain to be solved optimally [14]. Burgess et al [4] consider exact methods for the "classical resource leveling problem". In addition, they study the "overload problem", where costs are incurred if either a given supply of some renewable properties as a resources for the resource utilization is exceeded.

Burgess and Killebrew (1962) [4] introduced one of the first heuristics for resource leveling. This procedure is applicable to CPM/PERT networks consisting of nodes and temporal relations between arcs [4].

Woodworth and Willie (1975) has been extended this method to the multi-project and multi-resource. The above procedures cannot handle resource constraints. Results of past researches showed first constructive heuristic model has been developed by Neumann and Zimmermann (1999) [18] for the resource leveling problem with resource constraints, where it is shown that the general resource leveling problem in which there are precedence constraints between the tasks is NP-hard in the ordinary sense.

A local search heuristic and an exact method are evaluated in Neumann and Zimmermann (2000) [18]. The results of Ballestín et al. (2007) [1] shown resource leveling is applied in make-to-order manufacturing (but without resource constraints). Drexl and Kimms (2001) [7] introduced new methods for computing lower and upper bounds for the related resource investment problem.

Bła_zewicz et al. (1983) [2] introduced a classification scheme and provide several complexity results for machine scheduling under resource constraints. For a more comprehensive results and references, see the textbook of Bła_zewicz et al. (2001) [3]. Kellerer and Strusevich (2003) [12], Kellerer and Strusevich (2004) [13] identify dedicated parallel machines and different additional resources under various assumptions.

There is an incompatibility connection between the tasks such that only over more tasks may be executed in parallel works by Caramia and Dell'Olmo (2003) [5] which discuss various resource leveling problems where tasks have unit length and instead of machines. The authors discuss the computational complexity of several variants and propose a heuristic algorithm for solving those problems. Valls et al. (2009) [20] introduced a heuristic algorithm for scheduling workers of different skills where one of the objectives is to minimize the deviation of resource usage from the average load.

In a genetic algorithm, a population of candidate solutions (called individuals, creatures, or phenotypes) to an optimization problem is evolved toward better solutions. Each candidate solution has a set of properties (its chromosomes or genotype) which can be mutated and altered; traditionally, solutions are represented in binary as strings of 0 s and $1 \mathrm{~s}$, but other encodings are also possible[11].

Once resources are defined and assigned to the CPM activities, you are able to analyze the weekly accumulative effect of resources in your project plan. After this, the next step is controlling and optimizing your project plan. To do this, you need to modify your schedule to keep the allotment manpower requirements below your availability limit and level utilization occurs. This is called "resource leveling."

\section{Method}

\subsection{Definition of variables}

Table 1. Definition of variables

\begin{tabular}{|c|l|}
\hline Variables & Symbols \\
\hline $\mathrm{P}$ & Material \\
\hline $\mathrm{S}$ & suppliers \\
\hline $\mathrm{t}$ & Time period \\
\hline $\mathrm{fsp}$ & Float time of material to suppliers \\
\hline $\mathrm{tsp}$ & Order time of material to suppliers \\
\hline $\mathrm{jsp}$ & Order number in planning \\
\hline ospjsp & Amount of order from supplier in jsp duration \\
\hline VSspt & Material planning from supplier in per day \\
\hline ANVt & Number of Vehicles Available in per day \\
\hline Xspt & Carrying amount of material in per day \\
\hline Rspt & Material inventory \\
\hline
\end{tabular}




\begin{tabular}{|c|l|}
\hline NVst & The number of vehicles required to transport raw materials \\
\hline NVt & Number of vehicles required per day \\
\hline
\end{tabular}

\subsection{The objective function}

In this study, the objective function can be expressed as in terms of the following four specific conditions.

1. If the purpose of the uniform resource leveling and optimal utilization rate is a constant. The objective function in this case, minimizing the variance of utilization resource of transportation in planning and formulation is as follows:

$\min \sum_{t=1}^{T}(N V t-N V)^{2}$

That NV is the mean of resources required in planning.

2. If the target uniform resource leveling and optimal utilization rate is different for each period, the rate is determined by the user according to the current situation:

$\min \sum_{t=1}^{T}(N V t-A N V t)^{2}$

3. If the goal of minimizing the daily resource utilization distribution, the difference between the amount required to be a minimum of resources on different days. This function will determine how much time per day is allocated to minimized fluctuations in the level of resources required on consecutive days during the planning horizon:

$\min \sum_{t=1}^{T-1}\left(N V_{t+1}-N V t\right)^{2}$

4. If the goal isn't resource leveling and the objective is to minimize the number of vehicles in each period, The problem is formulated as follows:

$\min \sum_{t=1}^{T} N V t$

$\min t=1 T$

\subsection{Defining of constraints}

This problem's constrains as follow:

1. Order supplies

$\sum_{t=((j s p-1) * f s p)+t s p}^{(j s p * f s p)+(t s p-2)} X s p t=O s p j$

2. Carrying amount of raw materials:

Xspt $\leftarrow$ VSspt + Rspt -1

3. Equilibrium distribution:

Rspt $=$ Rspt $-1+$ VSspt $-X s p \quad \forall_{s, p, t}$

4. Number of vehicles required:

$N V W s t=\sum_{p=1}^{P} X s p t^{*} \mathrm{Wsp} / \mathrm{CW} ; \forall_{\mathrm{s}, \mathrm{t}}$ and $\mathrm{X} \geq 0$

$N V V \geq 0 ; N V W \geq 0 ; N V \geq 0 ; R \geq 0$

The population studied in this research, Provision of study materials required for the production of concrete plants in Iran. We used Visual Basic program for data analysis.

\section{Data Analysis}

Our proposed methodology is applied to Automobile plant in Iran is a conglomeration of a parent enterprise and its 127 subsidiaries engaged in development and implementation of Automobile production. The population studied in this research, Provision of study materials required for the production of Automobile plant in Iran. This section are included Sources of variance in both before and after the implementation of the model and then in a separate table, the impact of model changes to reduce costs and waiting times.

Table 2. Data for calculate variance of resources before implementation of the model

\begin{tabular}{|c|c|c|c|c|c|}
\hline $\mathbf{X}_{\mathbf{i}}$ & $\mathbf{F}_{\mathbf{i}}$ & $\mathbf{F}_{\mathbf{i}} \mathbf{X}_{\mathbf{i}}$ & $\mathbf{X}_{\mathbf{i}}-\overline{\boldsymbol{X}}$ & $\left(\mathbf{X}_{\mathbf{i}}-\overline{\boldsymbol{X}}\right)^{\mathbf{2}}$ & $\mathbf{F}_{\mathbf{i}}\left(\mathbf{X}_{\mathbf{i}}-\overline{\boldsymbol{X}}\right)^{\mathbf{2}}$ \\
\hline 1 & 37 & 37 & -16 & 256 & 9472 \\
\hline 2 & 3 & 6 & -15 & 225 & 675 \\
\hline 3 & 1 & 3 & -14 & 196 & 196 \\
\hline
\end{tabular}




\begin{tabular}{|c|c|c|c|c|c|}
\hline 4 & 1 & 4 & -13 & 169 & 169 \\
\hline 5 & 5 & 25 & -12 & 144 & 720 \\
\hline 6 & 3 & 18 & -11 & 121 & 363 \\
\hline 7 & 0 & 0 & -10 & 100 & 0 \\
\hline 8 & 2 & 16 & -9 & 81 & 162 \\
\hline 9 & 0 & 0 & -8 & 64 & 0 \\
\hline 10 & 2 & 20 & -7 & 49 & 98 \\
\hline 11 & 13 & 143 & -6 & 36 & 468 \\
\hline 12 & 5 & 60 & -5 & 25 & 125 \\
\hline 13 & 0 & 0 & -4 & 16 & 0 \\
\hline 14 & 1 & 14 & -3 & 9 & 9 \\
\hline 15 & 0 & 0 & -2 & 4 & 0 \\
\hline 16 & 0 & 0 & -1 & 1 & 0 \\
\hline 17 & 28 & 476 & 0 & 0 & 0 \\
\hline 18 & 1 & 18 & 1 & 1 & 1 \\
\hline 19 & 11 & 209 & 2 & 4 & 44 \\
\hline 20 & 3 & 60 & 3 & 9 & 27 \\
\hline 21 & 27 & 567 & 4 & 16 & 432 \\
\hline 22 & 3 & 66 & 5 & 25 & 75 \\
\hline 23 & 3 & 69 & 6 & 36 & 108 \\
\hline 24 & 8 & 192 & 7 & 49 & 392 \\
\hline 25 & 6 & 150 & 8 & 64 & 384 \\
\hline 26 & 33 & 858 & 9 & 81 & 2673 \\
\hline 27 & 4 & 108 & 10 & 100 & 400 \\
\hline 28 & 12 & 336 & 11 & 121 & 1452 \\
\hline 29 & 5 & 145 & 12 & 144 & 720 \\
\hline 30 & 2 & 60 & 13 & 169 & 338 \\
\hline Total & 219 & 3660 & & & 19494 \\
\hline & & & & & \\
\hline
\end{tabular}

Thus variance of resources before implementation of the model is:

$$
\bar{X}=\frac{\sum F i X i}{N}=\frac{3660}{219}=17 \quad \sigma=\frac{F i\left(X i-\overline{X i}^{2}\right.}{N}=\frac{19494}{219}=89.01
$$

Table 3. Data before implementation of the model

\begin{tabular}{|c|c|c|c|c|c|c|c|}
\hline Day & Mutation 1 & Mutation 2 & Mutation 3 & The waiting time for discharge & Waiting time at the bottleneck input & The estimated cost of waiting \\
\hline 1 & 250 & 400 & 250 & 1500 & 1560 & 4670000 \\
\hline 2 & 0 & 0 & 25 & 0 & 0 & 0 \\
\hline 3 & 0 & 0 & 0 & 0 & 0 & 0 \\
\hline 4 & 0 & 0 & 90 & 140 & 245 & 030000 \\
\hline 5 & 0 & 0 & 25 & 0 & 0 & 0 \\
\hline 6 & 0 & 560 & 0 & 740 & 300 & 2850000 \\
\hline 7 & 0 & 0 & 65 & 48 & 100 & 130000 \\
\hline 8 & 0 & 0 & 55 & 35 & 76 & 190000 \\
\hline 9 & 0 & 0 & 0 & 0 & 0 & 0 \\
\hline 10 & 150 & 80 & 90 & 390 & 268 & 885000 \\
\hline 11 & 0 & 470 & 110 & 580 & 950 & 0 \\
\hline 12 & 0 & 0 & 0 & 0 & 0 & 02000 \\
\hline 13 & 0 & 0 & 125 & 150 & 170 & 0 \\
\hline 14 & 0 & 0 & 0 & 0 & 0 & 0 \\
\hline 15 & 0 & 0 & 0 & 0 & 0 & 416000 \\
\hline 16 & 0 & 450 & 95 & 980 & 1100 & 0 \\
\hline 17 & 0 & 0 & 0 & 0 & 0 & 0 \\
\hline 18 & 0 & 0 & 0 & 0 & 0 & 844000 \\
\hline 19 & 220 & 0 & 35 & 330 & 280 & 0 \\
\hline 20 & 0 & 0 & 0 & 0 & 0 & 1910000 \\
\hline 21 & 0 & 460 & 85 & 690 & 160 & 610000 \\
\hline 22 & 0 & 0 & 120 & 180 & & \\
\hline
\end{tabular}




\begin{tabular}{|c|c|c|c|c|c|c|}
\hline 23 & 0 & 0 & 0 & 0 & 0 & 0 \\
\hline 24 & 0 & 0 & 0 & 0 & 0 & 0 \\
\hline 25 & 0 & 0 & 120 & 180 & 170 & 620000 \\
\hline 26 & 0 & 500 & 0 & 580 & 500 & 1570000 \\
\hline 27 & 0 & 0 & 0 & 0 & 0 & 0 \\
\hline 28 & 150 & 80 & 90 & 390 & 268 & 885000 \\
\hline 29 & 0 & 0 & 0 & 0 & 0 & 0 \\
\hline 30 & 0 & 0 & 0 & 0 & 0 & 0 \\
\hline Total & 770 & 3000 & 1380 & 6913 & 6767 & 16334000 \\
\hline
\end{tabular}

The variance of resources after implementation of the model is:

$$
\bar{X}=\frac{\sum F i X i}{N}=\frac{3930}{219}=18 \quad \sigma=\frac{F i\left(X i-\overline{X i}^{2}\right.}{N}=\frac{18074}{219}=82.52
$$

Table 4. Data after implementation of the model

\begin{tabular}{|c|c|c|c|c|c|c|}
\hline Day & Mutation 1 & Mutation 2 & Mutation 3 & The waiting time for discharge & Waiting time at the bottleneck input & The estimated cost of waiting \\
\hline 1 & 125 & 130 & 19 & 280 & 210 & 840000 \\
\hline 2 & 0 & 150 & 10 & 140 & 110 & 390000 \\
\hline 3 & 20 & 90 & 10 & 140 & 110 & 390000 \\
\hline 4 & 20 & 90 & 10 & 140 & 110 & 390000 \\
\hline 5 & 50 & 50 & 10 & 140 & 110 & 390000 \\
\hline 6 & 0 & 150 & 10 & 140 & 110 & 390000 \\
\hline 7 & 0 & 150 & 10 & 140 & 110 & 390000 \\
\hline 8 & 0 & 150 & 10 & 140 & 110 & 390000 \\
\hline 9 & 0 & 150 & 10 & 140 & 110 & 390000 \\
\hline 10 & 90 & 60 & 44 & 220 & 138 & 570000 \\
\hline 11 & 0 & 150 & 10 & 140 & 110 & 390000 \\
\hline 12 & 0 & 100 & 6 & 90 & 80 & 270000 \\
\hline 13 & 0 & 50 & 65 & 140 & 110 & 390000 \\
\hline 14 & 0 & 100 & 6 & 90 & 80 & 270000 \\
\hline 15 & 0 & 80 & 5 & 110 & 60 & 230000 \\
\hline 16 & 0 & 130 & 10 & 170 & 150 & 465000 \\
\hline 17 & 0 & 150 & 80 & 140 & 110 & 390000 \\
\hline 18 & 0 & 150 & 80 & 140 & 110 & 390000 \\
\hline 19 & 160 & 0 & 5 & 160 & 120 & 440000 \\
\hline 20 & 6 & 0 & 3 & 140 & 110 & 390000 \\
\hline 21 & 0 & 140 & 9 & 140 & 110 & 390000 \\
\hline 22 & 0 & 60 & 9 & 140 & 110 & 390000 \\
\hline 23 & 0 & 110 & 6 & 90 & 140 & 310000 \\
\hline 24 & 0 & 120 & 8 & 120 & 90 & 290000 \\
\hline 25 & 0 & 90 & 10 & 150 & 130 & 430000 \\
\hline 26 & 0 & 340 & 18 & 240 & 240 & 850000 \\
\hline 27 & 0 & 180 & 9 & 200 & 120 & 410000 \\
\hline 28 & 110 & 40 & 28 & 220 & 118 & 525000 \\
\hline 29 & 55 & 35 & 7 & 60 & 69 & 260000 \\
\hline 30 & 45 & 25 & 9 & 62 & 70 & 268000 \\
\hline Total & 681 & 3220 & 526 & 4362 & 3465 & 12278000 \\
\hline
\end{tabular}

Finally, the comparison of results before and after the implementation of the model is outlined.

Table 5. The comparison of results before and after the implementation of the model

\begin{tabular}{|c|c|c|c|l|}
\hline Decrease Percentage & Difference & After & Before & \\
\hline 40 & $46 \mathrm{~h}$ & $82 \mathrm{~h}$ & $128 \mathrm{~h}$ & The waiting time for discharge \\
\hline 53.5 & $69 \mathrm{~h}$ & $70 \mathrm{~h}$ & $139 \mathrm{~h}$ & Waiting time at the bottleneck input \\
\hline 25 & $4056000 \mathrm{Rial}$ & 12278000 Rial & 16334000 Rial & The estimated cost of waiting( per hour) \\
\hline
\end{tabular}




\section{Conclusion}

In this study consider project scheduling problems subject to overload activities, where the utilization of a set of Retrieval resources has to be smoothed over a prescribed planning horizon. Where project execution is to be decreased, and the so-called "overload problem", where costs are incurred if a given resource-utilization threshold is exceeded.

The view is determined by comparison of the model shown this model savings take for an average of about 50 percent of the time and 25 percent of cost. Despite this reduction in the cost of work duration, involving a change of production planning and implementing the project, the cost of this change is more than saving above in the short term.

In this paper, we consider the resource leveling was a real issue that was used to solve it by the genetic algorithm. Optimization method is used to solve this kind of problem is the Simplex method, But when the number of variables and constraints of the problem increases, this method loses efficiency. Genetic algorithm is the most effective Meta-heuristic method for solving problems and whatever the problem is larger the algorithm of most evident than other optimization methods.

According to the study results, it is clear that this algorithm is capable of very good solutions in an acceptable time offer. Other reasons for widely used genetic algorithm are simplicity.

\section{References}

Ballestin, F., Schwindt, C., Zimmermann, J., 2007.Resource leveling in make-toorder production: modeling and heuristic solution method. International Journal of Operations Research 13 (2), 76-83

Bła_zewicz, J., Lenstra, J.K., Rinnooy Kan, A.H.G., 1983, Scheduling subject to resource constraints: Classification and complexity. Discrete Applied Mathematics 5, 11-24

Bła_zewicz, J., Ecker, K.H., Pesch, E., Schmidt, G., Weglarz, J., 2001, Scheduling Computer and Manufacturing Processes, second ed. Springer-Verlag, Berlin

Burgess, A., Killebrew, J., 1962.Variation in activity level on a cyclical arrow diagram. Journal of Industrial Engineering 13, 76-83

Caramia, M., Dell'Olmo, P., 2003, Assessing the resource usage in scheduling with incompatibilities, OR Spectrum 25, 521-547

Demeulemeester, E., Herroelen, W., 2002. Project Scheduling: A Research Handbook. Kluwer, Bosten.

Drexl, A., Kimms, A., 2001. Optimization guided lower and upper bounds for the resource investment problem. Journal of the Operational Research Society 52, 340-351

Drótos M, Kis T, 2011, Resource leveling in a machine environment, European Journal of Operational Research 212, 12-21

Gather, T., Zimmermann, J., Bartels, J.-H., 2011.Exact methods for the resource levelling problem. Journal of Scheduling 14 (6), 557569

Hartmann, S., Briskorn, D., 2010, A survey of variants and extensions of the resource-constrained project scheduling problem, European Journal of Operational Research 207, 1-14

Iordache R, Moldoveanu F, (2014), "A Genetic Algorithm for Automated Service Binding", Procedia Engineering 69, 1162 - 1171

Kellerer, H., Strusevich, V.A., 2003, Scheduling parallel dedicated machines under a single non-shared resource. European Journal of Operational Research 147, 345-364.

Kellerer, H., Strusevich, V.A., 2004, Scheduling problems for parallel dedicated machines under multiple resource constraints. Discrete Applied Mathematics 133, 45-68.

Kolisch, R., Schwindt, C., Sprecher, A., 1999. Benchmark instances for project scheduling problems. In: Weglarz, J. (Ed.), Project Scheduling: Recent Models, Algorithms, and Applications. Kluwer, Boston, pp. 197-212

Lachmayer, R, Afsari, M, (2012). Algorithm of Converting Fuzzy GERT into CPM for Research Project Scheduling With Case Study, 8th International Conference of Project Management, Tehran, Iran

Lachmayer, R, Afsari, M, (2013), Fuzzy GERT method for Scheduling Research Projects, 9th International Conference of Industrial Engineering, Tehran, Iran

Neumann, K., Zimmermann, J., 1999.Methods for resource-constrained project scheduling with regular and non regular objective functions and schedule dependent time windows. In: Weglarz, J. (Ed.), Project Scheduling: Recent Models, Algorithms, and Applications. Kluwer, Boston, pp. 261-287

Neumann, K., Zimmermann, J., 2000.Procedures for resource leveling and net present value problems in project scheduling with general temporal and resource constraints. European Journal of Operations Research 127, 425-443

Rieck J, Zimmermann J, Gather T, 2012, Mixed-integer linear programming for resource leveling problems, European Journal of Operational Research 221, 27-37

Valls, V., Pérez, Á., Quintanilla, S., 2009. Skilled workforce scheduling in service centers. European Journal of Operational Research 193, 791-804

Woodworth, B.M., Willie, C.J., 1975, A heuristic algorithm for resource leveling in multi-project multi-resource scheduling. Decision Sciences 6, 525-540 